Vietnam Journal of Mechanics, NCST of Vietnam Vol. 25, 2003, No3 (186 - 192)

\title{
A MODEL OF SPREADING FOREST FIRES
}

\author{
V. D. QUANG, N. T. NAM*, H. D. LIEN**, \\ I. S. AntonOV ${ }^{* * *}$, T. T. KrastansKa*** \\ Faculty of Mechanical Engineering, \\ Hanoi University of Technology, Vietnam \\ * Faculty of Mechanical Engineering, \\ University of Technology, HoChiMinh city, Vietnam \\ ** Faculty of Mechanization and Electrification, \\ Hanoi Agricultural University, Vietnam \\ *** Department of Hydro-aerodynamics, \\ Sofia Technical University, Sofia, Bulgaria
}

\begin{abstract}
Current article describes a mathematical model for throwing burning wood material out of a main body of fire with a help of wind. A problem is solved by numerical way and it is given some of results, which are received during numerical experiment.
\end{abstract}

Forest fires are the most spread disasters especially during summer months in Bulgaria and in many other countries with temperate climate, and with big wood massive. Hundred thousand hectares wood and sowing are burnt during this summer in Bulgaria and Vietnam.

The fires are results from natural factors (thunder storms, high temperatures etc.) or from human carelessness and irresponsibility. These fires cause enormous pollution and damages. There is wind very often in mountain country and that helps spreading the fires. The wind raises and brings the burning branches out of the fire and very often puts them on behind people, who put out it, that's why spring up new fires. Reporters very often announce about new main bodies of the fire, which are spring up behind the fireman.

The current research is made because of the actuality of the problem and because of the enormous pollution and damages, which the fire causes.

\section{Mathematical model}

The problem is reduced to a non-isothermal two-phase turbulent jet, which is created over the main body of the fire and goes vertically up with initial $w_{0}$ speed is proportional to the fire's power $w_{0}=k \cdot Q^{1 / 5}$, where $k=1.9\left[M /\left(k W^{1 / 5} s\right] ; Q[k W]\right.$ is the power of the fire. The speed of the jet calms down when it goes up in vertical 
direction [1]:

$$
w(z)=\frac{k Q^{1 / 3}}{(z+1)^{1 / 3}} \quad[m / s]
$$

where $k=1.1\left[m^{4 / 3} /\left(k W^{1 / 3} s\right)\right]$.

This convective jet has very big kinetic energy and can bring up pieces from burning materials. Burning branches, which are brought up by the swift-flowing flows, are accepted as second phase of mixtures. It is accepted that the burning branches don't change their configurations during their fly until they fall on the earth.

There is a relative movement around the burning pieces and that's why it can not be extinct and it will be a potential source of the next fire. Most of the forests are in mountain places, where there is wind. The difference of the temperatures can cause wind too.

The model includes the movement of a piece from admixture (it is famous from the literature as Lagrange's method [2], [3]) and the gas flow created by the fire. The wind creates second gas flow and this gas flow is directed under definite angle towards the burning object.

The co-ordinate system, which we use, is presented in Fig. 1: the axis $x$ and $y$ are in the horizontal field, the axis $z$ is perpendicular to them.
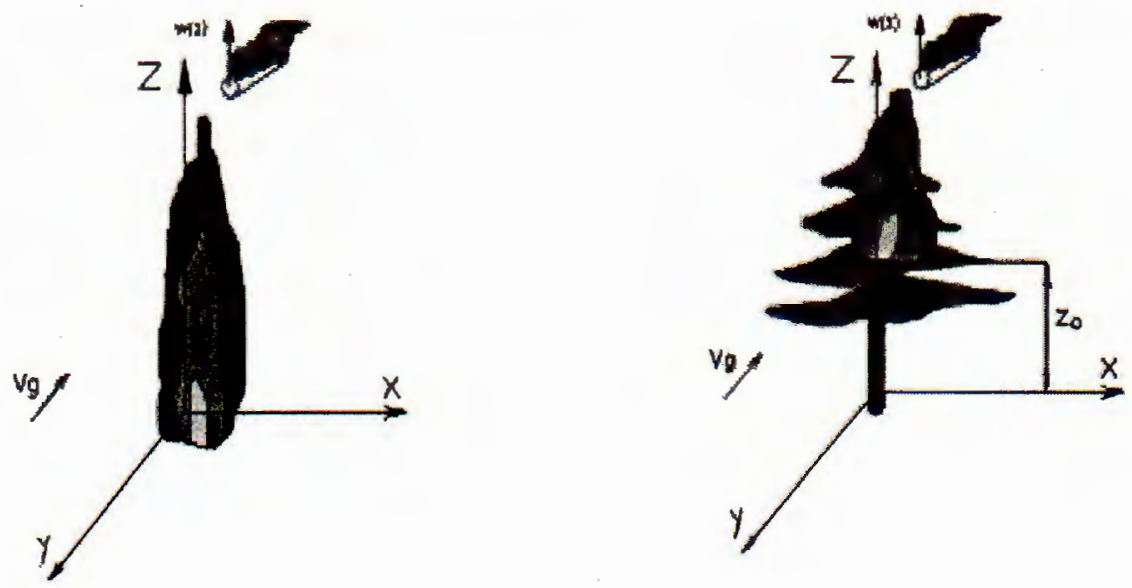

Fig. 1

The mathematical model is made with following assumptions:

- The power of the fire is constant all over the horizontal field $x-y$;

- The height of the fire's main body by axis $z$ direction becomes with translation of his main body and the equation (1.1) becomes:

$$
w(z)=\frac{1.1 Q^{1 / 3}}{\left[\left(z-z_{0}\right)+1\right]^{1 / 3}}[\mathrm{~m} / \mathrm{s}]
$$


where $z_{0}$ is the height of the fire's main body over the earth;

- The wind's direction is accepted as three-dimensional vector $V_{g}=V_{g}\left(u_{g}, v_{g}, w_{g}\right)$;

- It is possible to render an account for wind's stratification, which is very big in vertical field;

- The burning branch is a cylinder with length $\ell$ and diameter $D_{p}$, which have influence on aero-dynamical resistance coefficient $C_{R}[3]$ :

$$
C_{R}=\pi(0.128+12.8) / R e
$$

where: $R e=\left(u_{g}-u_{m}[0]\right) \cdot \ell / \nu ; u_{m}[0]$ - velocity of the burning branch in an initial moment $[\mathrm{m} / \mathrm{s}] ; \ell$ - typical size of the burning branch $[\mathrm{m}] ; \nu$ - gas viscosity $\left[\mathrm{m}^{2} / \mathrm{s}\right]$.

Lagrange's equations, for a movement of a piece of mixture, are formed with presented above assumptions and can be written as follows [3], [4]:

$$
\begin{aligned}
m_{p} \frac{d u_{p}}{d t}= & -0.5 C_{R} \rho_{g} S\left(u_{p}-u_{g}\right) \sqrt{\left(u_{p}-u_{g}\right)^{2}+\left(v_{p}-v_{g}\right)^{2}+\left(w_{p}-w_{g}\right)^{2}} \\
m_{p} \frac{d v_{p}}{d t}= & -0.5 C_{R} \rho_{g} S\left(v_{p}-v_{g}\right) \sqrt{\left(u_{p}-u_{g}\right)^{2}+\left(v_{p}-v_{g}\right)^{2}+\left(w_{p}-w_{g}\right)^{2}} \\
m_{p} \frac{d w_{p}}{d t}= & \left(\rho_{g}-\rho\right) w(z)^{2} \frac{\ell D_{p}}{2}-m_{p} g \\
& -0.5 C_{R} \rho_{g} S\left(w_{p}-w_{g}\right) \sqrt{\left(u_{p}-u_{g}\right)^{2}+\left(v_{p}-v_{g}\right)^{2}+\left(w_{p}-w_{g}\right)^{2}}
\end{aligned}
$$

where: $S$ - Midel's section: if the burning branch is taken out horizontally: $S=$ $D_{p} \cdot \ell$; if it is vertically: $S=\left(\pi \cdot D_{p}^{2}\right) / 4 ; m_{p}$ - The burning branche's weight, $m_{p}=\rho_{p} \ell\left(\pi \cdot D_{p}^{2}\right) / 4 ; \rho_{g}$ - Density of air at the surroundings temperature; $\rho$ - Density of air at the fire temperature; $D_{p}$ - Diameter of the burning branch.

The system of ordinary differential equations $(1.4) \div(1.6)$ is solved by RungeKuta's method with our own computer program and the initial conditions are strictly followed:

$$
t=0: \quad u_{p}(0)=0, \quad v_{p}(0)=0, \quad w_{p}(0)=0 .
$$

\section{Results from the numerical experiment}

Parameters, which are changed during the numerical experiment, are:

- Power of the fire $Q: 50,100,150 \mathrm{~kW}$;

- Size of the burning wood pieces: $\ell=0.2 \mathrm{~m} ; 0.3 \mathrm{~m} ; 0.5 \mathrm{~m}$; and $D_{p}=0.02 \mathrm{~m}$; $0.03 \mathrm{~m}$;

- Speed of the wind: $u_{g}=10,15,25 \mathrm{~m} / \mathrm{s}\left(v_{g}=w_{g}=0\right)$.

For all cases it is accepted that the temperature in the main body of the fire is $T=673 \mathrm{~K}$ and the temperature of the environment out of the fire is $T=293 \mathrm{~K}$ (Temperature equal to $20^{\circ} \mathrm{C}$ can be considered for normal for mountain in Bulgaria). In accordance to this $\rho_{g}$ and $\rho$ will equal 0.524 and $1.205 \mathrm{~kg} / \mathrm{m}^{3}$, respectively. It is 
necessarily to be said that the input information is arbitrary, the aim of that is to be shown the model and the program for its capacity.

The results of the numerical experiment are shown in fig. 2a-h, for the 5 cases with different diameters and lengths of the burning branch and for different velocity of the wind.

The basic conclusions are:

a) The smaller burning branch are taken further for the same velocity of the wind.

b) The wind helps for carrying away the burning pieces and that's why it is possible to burn out a new fire.

On fig. 2a-c a dependence of the length of the burning branch on the velocity of the wind is shown. The wind takes out the burning branch more difficult when it's length is bigger (when $\ell=0.2 \mathrm{~m}$ and $u_{g}=25 \mathrm{~m} / \mathrm{s}$ the burning branch is taken out on $34 \mathrm{~m}$ by axis $x$, but when $\ell=0.5 \mathrm{~m}$ and $u_{g}=25 \mathrm{~m} / \mathrm{s}$ the burning branch is taken out on only $22 \mathrm{~m}$ by axis $x$ ).

On fig. $2 \mathrm{~d}-\mathrm{f}$ it is shown that the influence of the wind is much bigger than the influence of burning branch's length. When the velocity of the wind is higher the wind will take out the burning branch further and further (when $u_{g}=10 \mathrm{~m} / \mathrm{s}$ and $\ell=0.5 \mathrm{~m}$ - the burning branch is taken out on $13 \mathrm{~m}$ by axis $x$, but when $u_{g}=25 \mathrm{~m} / \mathrm{s}$ and $\ell=0.5 \mathrm{~m}$ - the burning branch is taken out on $22 \mathrm{~m}$ by axis $x$ ).

All six figures show that the influence of the wind is bigger than the influence of the length of the burning branch.

Fig. 2a-c: $Q=50 \mathrm{~kW} ; D_{p}=0.03 \mathrm{~m} ; \ell=0.2 \mathrm{~m}$ (Fig. 2a), $0.3 \mathrm{~m}$ (Fig. 2b) and $0.5 \mathrm{~m}$ (Fig. 2c);

$u_{g}=10 \mathrm{~m} / \mathrm{s} \rightarrow \longrightarrow ; u_{g}=15 \mathrm{~m} / \mathrm{s} \rightarrow++++++; u_{g}=25 \mathrm{~m} / \mathrm{s} \rightarrow \ldots \ldots$

Fig. 2d-f: $Q=50 \mathrm{~kW} ; D_{p}=0.03 \mathrm{~m} ; u_{g}=10 \mathrm{~m} / \mathrm{s}$ (Fig. 2d), $15 \mathrm{~m} / \mathrm{s}$ (Fig. 2e) and $25 \mathrm{~m} / \mathrm{s}$ (Fig. 2f);

$\ell=0.2 \mathrm{~m} \rightarrow \longrightarrow ; \ell=0.3 \mathrm{~m} \rightarrow++++++; \ell=0.5 \mathrm{~m} \rightarrow \cdots \cdot-$.

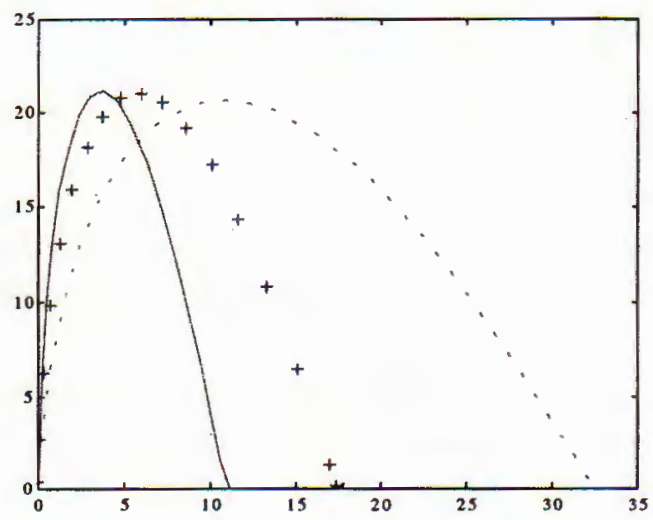

Fig. 2a

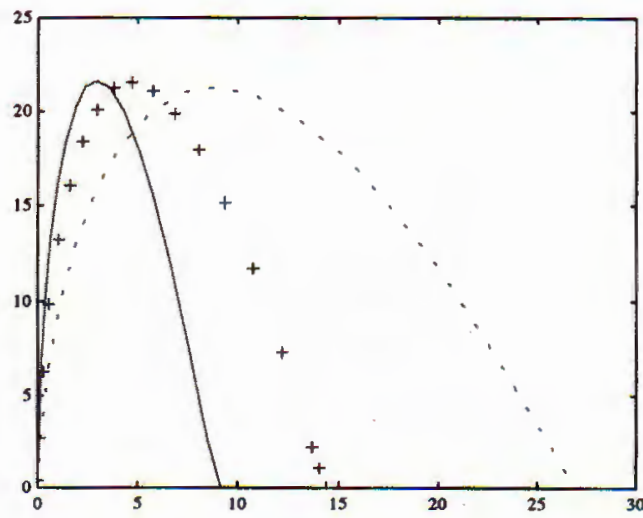

Fig. $2 b$ 


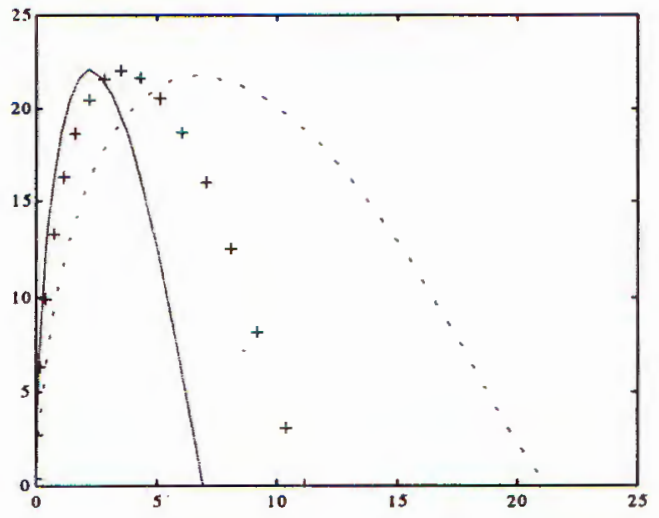

Fig. 2c

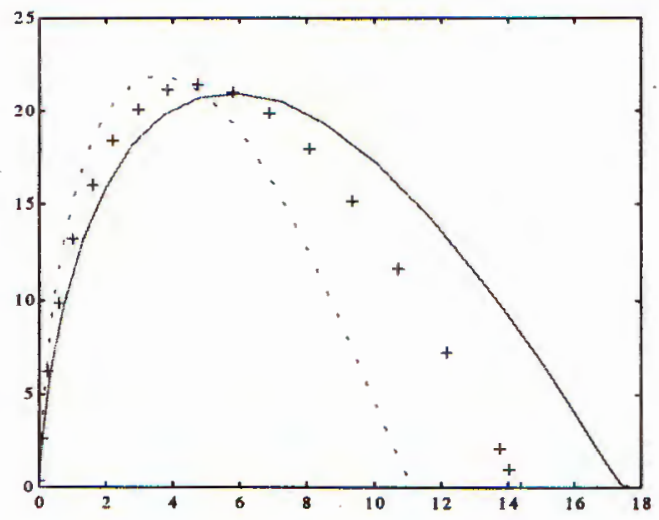

Fig. $2 e$

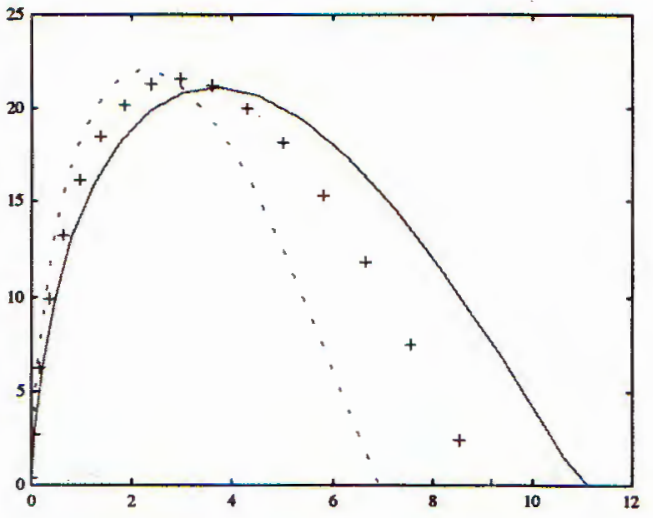

Fig. 2d

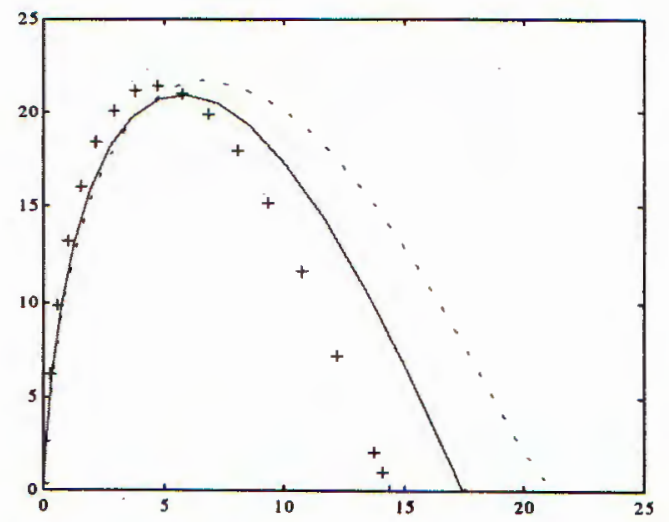

Fig. $2 f$

Fig. 2g: $Q=50 \mathrm{~kW} ; D_{p}=0.02 \mathrm{~m} ; \ell=0.2 \mathrm{~m}$;

$u_{g}=10 \mathrm{~m} / \mathrm{s} \rightarrow \longrightarrow ; u_{g}=15 \mathrm{~m} / \mathrm{s} \rightarrow++++++; u_{g}=25 \mathrm{~m} / \mathrm{s} \rightarrow \cdots$ Fig. 2h: $\ell=0.3 \mathrm{~m} ; D_{p}=0.03 \mathrm{~m} ; u_{g}=15 \mathrm{~m} / \mathrm{s}$;

$Q=100 \mathrm{~kW} \rightarrow \longrightarrow$; $Q=150 \mathrm{~kW} \rightarrow+++++++++$

On fig. $2 \mathrm{~g}$ it is shown that when the sizes of the piece are $\ell=0.2 \mathrm{~m}$ and $D_{p}=$ $0.02 \mathrm{~m}$ the influence of the wind is enormous, i.e. when $u_{g}=25 \mathrm{~m} / \mathrm{s}$ and the burning branch is with such size - it is taken out on $70 \mathrm{~m}$ by axis $x$.

All figures by now show the influence of the velocity of the wind $\left(u_{g}\right)$, the diameter of the burning branch $\left(D_{p}\right)$ and its length $(\ell)$ - influence only on the trajectory of the piece by axis $x$.

On fig. $2 \mathrm{~h}$ the influence of the power of the fire $(Q)$ on the burning branch's trajectory by axis $z$ is shown. When the sizes of the burning branch are $\ell=0.3 \mathrm{~m}$ 
and $D_{p}=0.03 \mathrm{~m}$ and $Q=100 \mathrm{~kW}$ - the piece is taken out on $20 \mathrm{~m}$ by axis $z$ and $16 \mathrm{~m}$ by axis $x$, but when $Q=150 \mathrm{~kW}$ - the piece is taken out on $40 \mathrm{~m}$ by axis $z$ and $29 \mathrm{~m}$ by axis $x$.

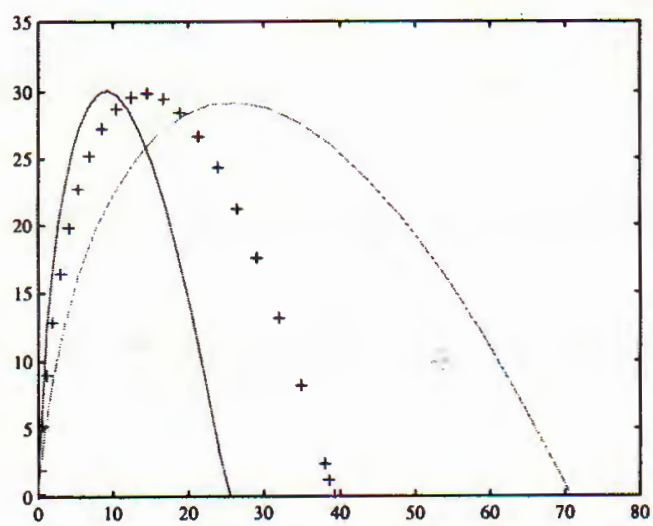

Fig. $2 g$

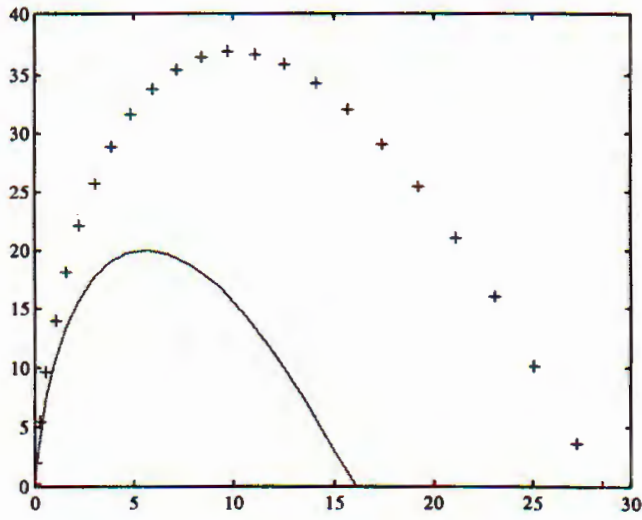

Fig. 2h

On fig. 3 it is shown the case when the main body of the fire is taken up by axis $\mathrm{z}$ respectively on $3 \mathrm{~m}$ and $6 \mathrm{~m}$.

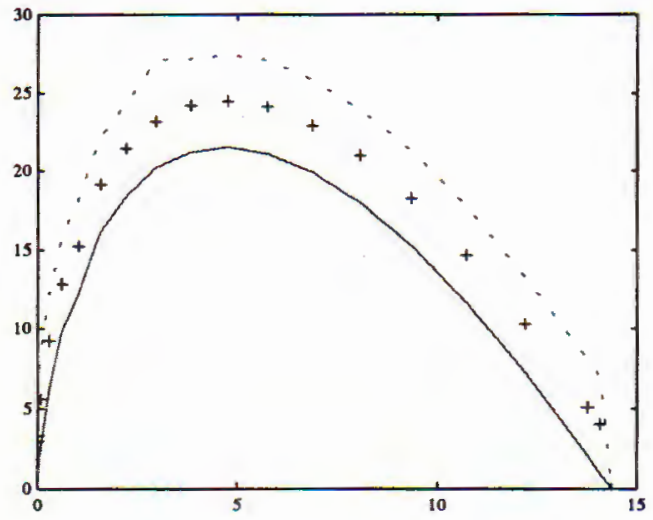

Fig. 3

Fig. 3: $\ell=0.3 \mathrm{~m} ; D_{p}=0.03 \mathrm{~m} ; u_{g}=15 \mathrm{~m} / \mathrm{s}$; $z_{0}=0 \mathrm{~m} \rightarrow \longrightarrow ; z_{0}=3 \mathrm{~m} \rightarrow+++++++++; z_{0}=6 \mathrm{~m} \rightarrow \ldots . .$.

\section{Conclusion}

We can say that the model in this researching is smaller the model of real fire. We accept that the burning is at the level of the earth but trees are tall and very 
often the beginning of the fire is at some meters from the earth. Our program allows to put the main body of the fire at some height.

The problems from this kind can be solved with help of the program and it allows to change all parameters, which influence on this unpleasant phenomenon.

\section{REFERENCES}

1. Drysdale D., An Introduction to Fire Dynamics, John Wiley and Sons, New York 1985.

2. Nigmatulin R. I. Basic of mechanics of heterogeneous media, Nauka, Moscow 1978.

3. Antonov I. S. Modeling of the two-phases turbulent jets, Autoreferat for doctor dissertation, Sofia, 1995.

4. Scheiber A. A. et al, Turbulent Gas Flow, Fluid and Gas Mechanic (VINITI), Moscow 1991.

Received December 27, 2001

in revised form July 1, 2003

\section{MÔ HÌNH VỀ SỰ LAN TỎA CHÁY RỪNG}

Bài báo trình bày nghiên cứu về sự lan tỏa các yếu tố cháy từ đám cháy rừng dưới tác động của gió. Vấn đề được giải quyết bằng phương pháp số. Đã phân tích một số kết quả nhận được từ tính toán số. 